Article

\title{
Key Aspects for IT-Services Integration in Urban Transit Service of Medium-Sized Cities: A Qualitative Exploratory Study in Colombia
}

\author{
Tomas Ramirez-Guerrero $^{1,2, * \mathbb{D}}$, Mauricio Toro ${ }^{1,2,3} \mathbb{( D}$, Marta S. Tabares ${ }^{3}\left(\mathbb{D}\right.$, Ricardo Salazar-Cabrera ${ }^{4}$ \\ and Álvaro Pachón de la Cruz ${ }^{5}$ iD
}

check for updates

Citation: Ramirez-Guerrero, T.; Toro, M.; Tabares, M.S.; Salazar-Cabrera, R.; Pachón de la Cruz, Á. Key Aspects for IT-Services Integration in Urban Transit Service of Medium-Sized Cities: A Qualitative Exploratory Study in Colombia. Sustainability 2022, 14, 2478. https://doi.org/ $10.3390 /$ su14052478

Academic Editors: Stefano Carrese and Sergio Maria Patella

Received: 9 December 2021

Accepted: 9 February 2022

Published: 22 February 2022

Publisher's Note: MDPI stays neutral with regard to jurisdictional claims in published maps and institutional affiliations.

Copyright: (c) 2022 by the authors. Licensee MDPI, Basel, Switzerland. This article is an open access article distributed under the terms and conditions of the Creative Commons Attribution (CC BY) license (https:// creativecommons.org/licenses/by/ $4.0 /)$.
1 Maintenance Research Group (GEMI), Universidad EAFIT, Medellin 050022, Colombia; mtorobe@eafit.edu.co 2 Intelligent Transportation System Undergraduate Research Group (SiSIT), Universidad EAFIT, Medellin 050022, Colombia

3 R\&D\&I in Information and Communication Technologies Research Group (GIDITIC), Universidad EAFIT, Medellin 050022, Colombia; mtabares@eafit.edu.co

4 Telematics Engineering Research Group (GIT), Telematics Department, Universidad del Cauca, Popayan 190001, Colombia; ricardosalazarc@unicauca.edu.co

5 Information Technology and Telecommunications Research Group (I2T), ICT Department, Universidad Icesi, Cali 760001, Colombia; alvaro@icesi.edu.co

* Correspondence: teramirezg@eafit.edu.co

\begin{abstract}
In the last ten years, approximately, urban transit systems of Latin American capital cities have evolved significantly. Colombia, specifically, has concentrated this development in its capital cities, consolidated through digital transformation programs in the transportation sector. However, the same phenomenon does not occur in medium-sized cities for different reasons that are important to analyze. This paper presents an exploratory qualitative study involving eight medium-sized cities in the implementation phase of their strategic urban transit systems. Three main aspects that drive this study were identified: technologies and their cost, functional requirements to implement information technology services in transit systems, and economy and administration associated with this type of implementation. Based on this, a semi-structured interview data collection instrument was designed, with the participation of 15 officials distributed in the eight target cities, and one expert from an intelligent transportation system in a capital city. With the information collected, an exploratory analysis was made contrasting the responses given by each interviewee. The most relevant results show that the interviewees prioritize technologies based on open standards to provide information to users; that the northern medium-sized cities of the country do not have strategies that regularize and motivate the use of public transportation; instead, the southern medium-sized cities of the country consider the use of transportation to be necessary. Finally, it was concluded that the information technology services to be included in the provision of transit services should promote these cities' cultural and economic growth.
\end{abstract}

Keywords: information technology; public transportation; interviews; IT services; functional requirements; intelligent transportation systems; prioritization

\section{Introduction}

Urban transit systems (UTS) influence the economy and infrastructure of cities. UTS are shared by most citizens and directly affect their well-being [1]. Transit in a city responds to (i) changes in the mobility patterns of its inhabitants, (ii) increment in transportation alternatives, (iii) vehicular congestion, and (iv) effects on the environment caused by the automobile fleet [2].

Faced with the concentration of city populations and the increasing needs of society in terms of mobility, intelligent transportation systems (ITS), for passengers, contribute to (i) a better environment, (ii) life quality, and (iii) sustainability in urban areas [3]. As an 
example, the medium-sized city (MSC) of Piraeus, in Greece, had a population of 200,000 and faced heavy traffic congestion. This problem was reduced with the implementation of intelligent traffic-light control systems, reducing traffic jams by $20 \%$ to $50 \%$, depending on the time of day analyzed; travel times by $8 \%$ to $12 \%$; and air pollution by $10 \%$ to $17 \%$ [4]. Additionally, to ensure the sustainability of mobility and infrastructure, Piraeus provided various means of public transportation-such as electric shuttle buses and small electric cars-to drive specific routes around downtown or to visit designated access points [5].

Despite the success of Piraeus, in many MSC, in developing countries, an effective and efficient UTS is far from being a reality. This is the case of India, where different means of transportation, in MSC and towns, correspond to informal means that compete to supply the mobility needs and demands of the population [6]. In the last decade, several proposals, aimed to improve UTS and sustainable mobility, have emerged in Latin American countries, especially, in the UTS of Colombian, Peruvian, Panamanian, Argentinean, and Brazilian MSC [7]. These proposals approach from reforms with the formulation of specific policies to improve mobility in developing countries [8], to the integration of technological systems to meet the needs in mobility and generate value in the transit service of Latin American cities [9]. One of these proposals is the design of Strategic Public Transportation Systems (SETP, in Spanish), which consist of restructuring UTS, in Colombia's MSC, to (i) improve service provision through the adaptation of road infrastructure and (ii) implementation of information technology (IT) based solutions [10,11]. The purpose of SETP is to achieve (i) safe, (ii) integrated, (iii) efficient, (iv) accessible (v), and sustainable mobility, while integrating IT services based on ITS [12]. During the design and implementation of SETP, the Colombian government has focused its efforts on the integration of IT systems in the three major components of the UTS: (i) fleet management and control system (FMCS), (ii) collection management system (CMS) and, in a few cities, (iii) traffic light and traffic control system. The main benefits of technological integration, in UTS, are focused on the improvement of FMCS [13]. However, this component encompasses the inclusion of a significant number of ITS services.

Likewise, in Colombia, the use of private vehicles has increased to the detriment of UTS, with an annual increase of $14.7 \%$ in motorcycles and $6.6 \%$ in automobiles [14]. The Colombian MSC (i.e., between 250,000 to 600,000 inhabitants), like as Sincelejo (Sucre state) reflects the consequences of the high use of motorcycles for individual trips: (i) increase of emissions; (ii) increase of informal transportation; (iii) negative impacts on the use of transit service, and (iv) a high number of accidents and road safety incidents. Besides, MSC must share the road infrastructure with other vehicles, which requires adequate control and monitoring to solve problems such as (i) route compliance, (ii) speed control, and (iii) control at passenger stops $[8,15,16]$.

Despite the praiseworthy goals of SETP, of the eight SETP prioritized and co-financed by the Colombian government, only two MSC have started their commercial operation, with the following two causes of delays: (i) delay in the construction of the required transportation infrastructure, with an advance of $46 \%$ of the total kilometers completed [17]; (ii) acquisition of the necessary information systems and technologies to control the fleet, deliver information to the users and fare-payment collect [11]. Furthermore, during 2020, occupancy capacity, in UTS, was limited to $35 \%$ due to the COVID-19 pandemic, adding the confinement of people and the fear of contagion, in UTS, as new barriers that generated economic losses for this sector [18].

Thus, in this research, it is important to answer the following research questions (RQ) to understand how Colombian MSC should structure their digital transformation projects to achieve the objectives proposed in SETP.

- RQ1: What type of technologies have been considered by UTS companies (in charge of implementing the SETP in Colombia), to achieve an improvement of transit service in these cities?

- $\quad \mathrm{RQ2}$ : What are the key functional requirements of the SETP in the process of being implemented in Colombia, for MSC in developing countries? 
- RQ3: What other aspects (economic and/or administrative) are important for UTS companies in Colombia, to achieve adequate technology integration in ITS projects?

This paper presents an exploratory qualitative study involving eight medium-sized cities in the implementation phase of their urban transit systems. This study seeks to answer the above questions. Thus, a semi-structured interview data collection instrument was designed, with the participation of 15 officials distributed in the eight MSC studied, and one expert from an intelligent transportation system in a capital city. With the information collected, an exploratory analysis was made contrasting the responses given by each interviewee, to recognize the key aspects in IT-services integration that offer a functional improvement and sustainable operation to UTS, in Colombian MSC.

The structure of this paper first presents a background, followed by a complete description of the research methodology. After, the main findings are presented in the core of the document: the categories that define the key aspects for the integration of IT services, in UTS, in Colombian MSC. Following, data coding is presented showing the progress from the raw data to the aggregated theoretical categories. Finally, the study is summarized in the concluding discussions and conclusions, and future work is presented.

\section{Background}

In this section, concepts and previous research that support this research are presented.

\subsection{Concepts}

Sustainable development is the organizing principle to satisfy the needs of present society, sustaining the capacity of natural systems to provide the natural resources on which the economy and society depend, without compromising the ability of future generations to satisfy their own needs [19].

Many processes associated with transit services are clearly not sustainable, given that increased activity in the transportation sectors can grow much faster than a region's economy [20]. In fulfilling their main objective of providing mobility, transportation systems generate numerous impacts, both negative (e.g., accidents, noise pollution, and greenhouse gas emissions) and positive (e.g., regional economic development and strengthening of agglomeration advantages).

Because of their magnitude of UTS, these systems play a relevant role in the economy and sustainability of cities, generating strong demands for inputs (e.g., infrastructure, technology, jobs, and fuel) [21]. Currently and in the medium term, an important objective of UTS in both developed and developing countries is to continuously improve sustainability by managing the growing demand for passenger transportation efficiently, effectively, and safely, and mitigating direct and indirect impacts on the environment, the economy, and society [22,23].

Therefore, in the search for the construction of sustainable urban environments, prominent industries such as the transportation sector consider that technological and social trends are within the future functionalities implemented in cities. Some of these trends are based on technologies such as the Internet of Things (IoT), where key services for parking management are automation and transportation. Technologies are also key for other services such as commercial fleet management and vehicle telematics [24]. Like this trend, the integration of various information technologies in transportation can improve operation and service delivery.

The level of IT integration, in the context of transit services, has been evidenced in applications such as electronic booking, trip planning, and real-time service. Transportation systems-in large-sized cities such as Bogotá, Buenos Aires, Curitiba, Mexico City, and Rio de Janeiro—have mobile applications that provide the previously mentioned services [2]. 


\subsection{Previous Research}

Previous research can be classified into four groups: (i) solutions to improve sustainability, (ii) reference frameworks, (iii) vehicle tracking, and (iv) artificial intelligence applications.

In the first group, the inclusion of technologies to achieve transportation systems in Ilorin (Nigeria), has demonstrated operational efficiency in the areas of vehicle scheduling and trip booking, reduction of waiting times, user assistance, and comprehensive historical recording of bookings and trips [25]. For Colombian MSC, the criteria with the greatest influence on transportation mode selection for users are walking and waiting time [26]. Thus, several research works were developed to design technological solutions and best practices to improve service provision in UTS, such as (a) automatic detection of traffic infractions [27,28], (b) evaluation of transit drivers [29], and (c) identification of functional requirements of low-cost IT systems to optimize the performance of UTS in Colombian MSC [30,31]. From another perspective, [32] presented other solutions aimed to promote the daily use of non-motorized means of transportation, and to encourage the improvement and sustainability of mobility in an MSC. These modes of transportation (e.g., public bicycle systems) have a great global expansion, with a diversity of equipment, IT services, and technological alternatives (e.g., online platforms for bicycle lending). Therefore, the authors proposed a project focused on implementing technologies of non-motorized means of transportation, including these means in the mobility master plan that seeks to focus urban development towards the sustainability and humanization of the city.

Regarding the second group, the above examples showed the opportunity to improve transit service delivery using ITS, which requires a strong commitment from all stakeholders, in the transit sector, and employing reference frameworks to implement ITS technologies. Thus, in [33] it was proposed the design of ITS services for Colombian MSC under internationally adopted reference frameworks, such as Architecture Reference for Cooperative and Intelligent Transportation (ARC-IT) and Framework Architecture Made for Europe (FRAME) [34]. The methodology employed was used for two mobility services designs: monitoring of transit vehicles and measurement of traffic. For this purpose, the authors proposed the use of onboard equipment $(\mathrm{OBE})$ in the vehicles to be monitored. Likewise, in $[35,36]$ it was proposed an FMCS design with ITS services supported on a reference framework, considering financial limitations and needs to adopt technologies that enhance the transit relevance features in MSC. Therefore, the authors presented a literature review that allowed to identify the key requirements for these systems, construction of a prototype with suggested technologies such as Long-Range Wide-Area Network (LoRaWAN), and some experimental tests to evaluate the performance of the designed prototype.

The third group includes one previous research where an information system was developed to improve passenger mobility, in a UTS, in a developing Latin American country [37]. The system is composed of a transit vehicle tracking system, a mobile application that presents the information to users in real-time, a website to observe the data captured from the transportation system. Moreover, in [38] it was evaluated the use of prototypes, using LoRaWAN, in operating conditions in a vehicle tracking service of an MSC. The prototype was developed based on ITS architectures and IoT. The results obtained from the six experimental tests performed showed the assertive behavior of transmissions using LoRaWAN may be feasible to implement in transit systems.

Finally, four group includes a study where it was presented the technological adoption of a Colombian capital city in its transition to a smart city, and how mobility and transit system failures can be solved through the development of predictive models based on artificial neural networks [39]. Such models aim to control and manage the city's traffic light systems. As part of the results, the authors presented a rigorous evaluation of different neural network algorithms that can be used to reduce congestion on the city's main roads. Furthermore, the inclusion of artificial intelligence and advanced analytics in UTS can also contribute to improving service delivery. In [40] it was presented an overview of artificial intelligence techniques that are applied, in different latitudes, to 
manage transportation problems. These techniques solve problems associated with urban mobility, traffic management, transit, and road safety, indicating the advantages and limitations of artificial intelligence applications in each of these.

\section{Materials and Methods}

The methodological application of this research was based on two aspects. First, the background presented above, which required a search for previous research related to intelligent transportation and transit systems in MSC. Second, the empirical results of an exploratory qualitative study conducted in eight (8) MSC of Colombia, with the participation of the Chief Operating Officers (COO), Chief Technology Officers (CTO), and other decision-makers of the government companies that are implementing the Strategic Public Transportation Systems in Colombian MSC.

\subsection{Research Approach}

This research was defined as a qualitative study, which can be defined as any research that produces significant findings that cannot be reached by statistical procedures or other quantitative methods [41]. From this perspective, it is possible to address research on organizational performance, social and cultural phenomena, and interactions between populations. This is the case of transportation, as an important sector within the dynamics of a city.

Data in this research were obtained by means of semi-structured interviews, an effective method to capture interviewees' explicit comprehension of a phenomenon [42]. In this type of interview, participants receive very similar stimuli, and it does not involve a unique sequence for all interviewees [43]. This was done with the aim to identify notions and relationships in the raw data, and then organize them into an explanatory theoretical scheme [41]. Similarly, a sampling of events representative of significant theoretical abstractions was carried out, using semi-structured interviews as instruments to obtain information. These interviews were then compared with each other, in the search for properties and dimensions, considering the range or variation in the dimension as the main factor.

\subsection{Participants}

At present in Colombia, eight (8) MSC have a SETP, are in the system-implementation, and have design and financial resources allocated; while another four (4) similar cities are in the design phase of their SETP, awaiting budget allocations for their transit service projects [44]. For this study, the eight MSC that have a SETP in implementation were selected, covering all the participating organizations available in the universe of this research. These cities are characterized by a population between 250,000 and 600,000 inhabitants, which is a requirement to have a SETP [10]. Figure 1 illustrates the location of the eight MSC that were selected in this study. The color scale on the map indicates the approximate number of inhabitants in each of these cities.

This research focused on a discriminate sampling that included a total of nine (9) interviews conducted with the COO or CTO of UTS companies in the selected MSC. Of the nine interviews conducted, eight interviews were conducted with SETP officials in the target cities. Fifteen (15) officials (COO, CTO, and others) from these MSC-that correspond to all the municipalities implementing a SETP_participated in the interviews. At least one official in charge of making operational or technological decisions, from each of the UTS companies (located in 8 different cities in the country), there is total coverage of the MSC involved in this type of transit service improvement projects, collecting the points of view of each one of the particular contexts that could occur in MSC located in different geographical points, with particularities in terms of road conditions, functional requirements, type of users, and socio-economic situation. It should be noted that the officials interviewed in each of the UTS companies have had continuous contact with different stakeholders in 
their cities (from the government sector, citizens, among others) in the last 5 years, which allows them to have a broad vision of the specific situation in each city.

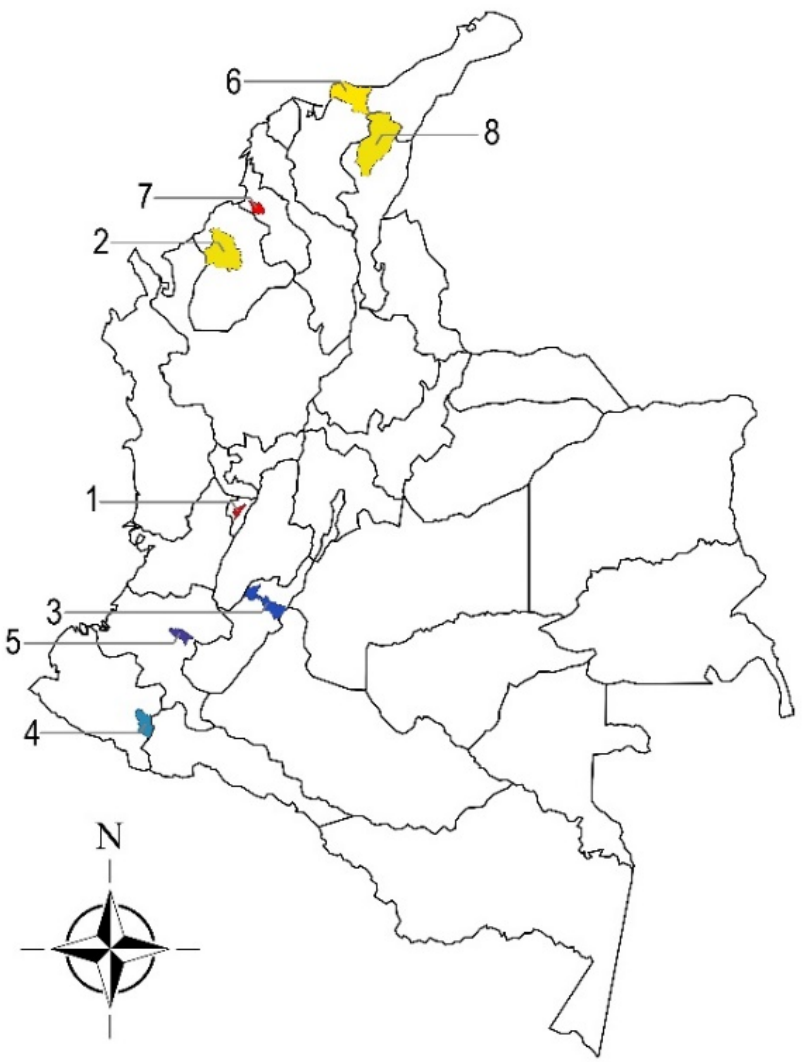

\section{Population (in thousands)}

500

375

250

\section{Cities}

1. Armenia

2. Montería

3. Neiva

4. Pasto

5. Popayán

6. Santa Marta

7. Sincelejo

8. Valledupar

Figure 1. Colombian MSC that are in the system-implementation phase of a SETP.

Furthermore, the ninth interview was conducted with the operator of an Integrated Mass Transportation Systems (SITM, in Spanish), from a capital city in Colombia, which is a Latin American success story that serves as a world benchmark for UTS on issues of best practices and innovation [14]. A SITM is the organized combination of infrastructure and equipment in a UTS of large-sized Colombian cities (i.e., over 600,000 inhabitants), that covers a high volume of passengers and responds to a significant percentage of mobilization needs in a defined area of influence. Adding the R\&D official consulted in this ninth interview, a total of 16 officials were interviewed in the sessions conducted, representing a total of 9 different transit companies. Table 1 summarizes the demographic information about the 16 officials that participated in the interviews.

Table 1. Demographic information of participants.

\begin{tabular}{ccc}
\hline Characteristics $(\boldsymbol{n = 1 6 )}$ & $\boldsymbol{n}$ & $\mathbf{\%}$ \\
\hline Position & & \\
Chief Operating Officer (COO) & 7 & 43.7 \\
Operations Assistant (OA) & 4 & 25.0 \\
Chief Technology Officer (CTO) & 3 & 18.8 \\
Others * & 2 & 12.5 \\
& $\mathbf{M ~ ( S D )}$ (K) \\
\hline Experience (in years) & $6.2(4.7)$ & $1.8(4.4)$ \\
\hline M= mean, SD = standard deviation, S = skewness, K = kurtosis. ${ }^{*}$ This item includes planning and R\&D managers.
\end{tabular}

Table 2 shows the number of participating officials for each of the MSC studied. It also includes the SITM official interviewed. It should be noted that in several interviews the $\mathrm{COO}$ decided to participate with all members of the operations and technology team, to 
receive support on specific domain issues during the interview. In other cases, only one official from the UTS company attended, although the invitation had been extended to the entire operations and technology team. One detail to note is that in some of these cities, operations and technology management are grouped in a single position (preferably in the $\mathrm{COO})$.

Table 2. Numbers and positions of officials from each city who participated in the interview sessions.

\begin{tabular}{|c|c|c|c|c|c|}
\hline \multirow{2}{*}{ City } & \multicolumn{4}{|c|}{ Position } & \multirow{2}{*}{ Total (by City) } \\
\hline & $\mathrm{COO}$ & OA & СТO & Others & \\
\hline Armenia & 1 & - & 1 & - & 2 \\
\hline Monteria & - & - & 1 & - & 1 \\
\hline Neiva & 1 & 1 & - & - & 2 \\
\hline Pasto & 1 & - & - & 1 & 2 \\
\hline Popayán & 1 & 3 & - & - & 4 \\
\hline Santa Marta & 1 & - & - & - & 1 \\
\hline Sincelejo & 1 & - & 1 & - & 2 \\
\hline Valledupar & 1 & - & - & - & 1 \\
\hline SITM & - & - & - & 1 & 1 \\
\hline Total (by position) & 7 & 4 & 3 & 2 & 16 \\
\hline
\end{tabular}

\subsection{Interview Procedure}

Because of the pandemic caused by COVID-19, the stages of this research were conducted under the measures of confinement and social distancing. Online qualitative research through video interviews, network focus groups, documentary searches on the web and in digital databases, requires techniques that facilitate the work without requiring physical face-to-face interaction. The use of digital media, in multiple daily facets, leads researchers to understand that they are facing a new research era [45].

Considering the above, the interviews with SETP officials were carried out in accordance with the following steps:

1. Interviews were conducted via videoconferencing using the Microsoft Teams of the Office 365 suite.

2. The interviews were recorded on video with the consent of each participant, which was requested from the interviewees at the beginning of each session.

3. In each session, a semi-structured interview was conducted with the participants, each of which lasted approximately 60 to $80 \mathrm{~min}$.

4. Sixteen (16) baseline questions (provided in Appendix A) were asked of participants during the interview. These questions were developed based on concepts derived from the literature, previous research, and following the interview design process to obtain the desired information $[41,46,47]$. During the interviews, emphasis was placed on the information provided by the officials interviewed in the videoconference sessions.

5. Moreover, six (6) complementary questions (provided in Table A1, Section 4) based on the 5-level Likert scale [48], were conducted to identify the prioritizations established by each city regarding the integration of IT services in transit service. This scale was used as a basis for measuring the relevance of the functional requirements of the system, the technology to be adopted, and the system components to be prioritized.

6. Closing the interview, the interviewees were given space to add topics that were not mentioned and that are related to the objective of this study, the recording ended, and the attending officials were thanked for their participation.

Table 3 shows the items used as multiple-choice answers to the supplementary questions asked to the interviewees, based on the 5-levels Likert scale, being these levels used to measure the low or high importance in each consultation. 
Table 3. Likert scale levels used in the interviews.

\begin{tabular}{cc}
\hline Item Response & Value \\
\hline Not important & 1 \\
Not very important & 2 \\
Something important & 3 \\
Important & 4 \\
Very important & 5 \\
\hline
\end{tabular}

\subsection{Data Coding}

Interview recordings were transcribed verbatim by research assistants, with each transcription ranging in length from 11 to 16 single-spaced pages. Finalizing the empirical phase, the total amount of qualitative data obtained was 122 pages of single-spaced transcriptions. The transcriptions were analyzed using qualitative content analysis due to the specific but exploratory nature of this study. Therefore, the interviews data were analyzed using as tools (a) the use of questions that generate ideas or ways of examining the data (b) the analysis of words, phrases, and sentences to raise questions about possible assumptions derived from the data, (c) further analyses by systematic comparisons of two or more phenomena-an incident from the data against one drawn from experience or taken from the literature-to identify categories and develop them [41,43].

Similar data patterns were systematically classified and grouped for data analysis. For this purpose, the data were structured by first-order selective coding through logic-driven discriminative sampling. Selective coding involves moving to a higher level of conceptualization with the constructs developed, establishing relationships, and determining a central category that connects with the other categories and relates them to each other [49]. During the process of coding, iterated comparisons were made between the general theories and the empirical data collected during the interviews, using the first-order categories (based on the data) together with the concepts from the general theories to develop the definition of the key aspects that influence the integration of IT-services in a transit service of MSC. It is significant to note that in discriminate sampling it is important to have a certain degree of consistency given that the comparisons were made systematically in each category, following the sections sequence of the interview guide (see Appendix A). Besides, data collections during coding were guided by information analysis, which was performed in parallel to data sampling.

Therefore, the aim of selective coding was to integrate and refine the categories to form a larger theoretical scheme, using story argument writing and note review as analytical techniques [41]. Based on this, the central category was determined (corresponds to the most relevant key aspect), which should be transversal to the others. Next, the theory is refined by removing excess data and completing the remaining categories, thus preparing the theory and data for validation.

\subsection{Discriminate Sampling and Data Validation}

Discriminate sampling consists of a highly selective choice where the researcher chooses documents, people, and sites that increase the comparative analysis opportunities. This process may involve revisiting sites, documents, or people, or exploring new sources to get the data needed to saturate the categories and conclude the study [41].

Both the COO and CTO interviewed had an average of more than five years of experience in the transportation sector, are high-ranking officials within the government companies, and are the decision-makers on the planning, adoption, and use of technologies, and implementation of standards in transit in MSC.

With the systematic classification and grouping of similar data patterns made during sampling and coding, the comparative analysis was made by contrasting the information obtained during the interviews with the information provided by the SITM operating company, and with national studies associated with UTS $[8,11,26]$. The answers given by the different interviewees to the sixteen basic questions were compared with each other 
and with the validation information. The data were validated, simultaneously, at each step of the sampling and analysis, with additions or modifications being applied as new data came into the research. Thus, the interpretations made were affirmed or denied. Only concepts that meet all requirements of the rigorous comparison process became part of the theory. Discriminate sampling ended when the categories obtained from the analyzed data were saturated.

\subsection{Categorization}

Categorization is the process of labeling or classifying data units, which is performed during the coding process. The essence of categorization is to identify a unit of data as pertaining to, representative of, or exemplifying some more general phenomenon [49].

After many concepts were compiled in the discriminate sampling, the first step of the analysis determined the central category and the remaining categories that are related to it by means of the phrases that explain the connection. The second step consisted of reviewing the theoretical scheme to find its internal consistency and logic, starting from the central category itself. The third step consisted of completing the poorly developed categories and, finally, validating the theory by comparing it with the raw data or data taken from experience [41].

In this study, the central category corresponds to the key aspect with the greatest relevance in the integration of IT services in UTS in MSC. From this, the categories that define the most significant influential aspects that should be considered to integrate IT services in UTS were established. These aspects can contribute to improving the operational processes of transit systems in Colombian MSC, making them more competent and sustainable. The categories resulting from this research are presented in the Section 4 of this paper, as subsections.

\section{Results}

The results of this study are divided into the categories resulting (technological, economic, and administrative aspects).

\subsection{Technological Aspect: Technology Features and Functionalities}

The technological aspect was the central category and transversal to the other categories, within the most relevant factors at the time of integrating IT services in UTS, in MSC. The officials interviewed expressed the service prioritizations defined and their relationship with the technological functionalities to be included in their UTS. Figure 2 shows the word cloud related to the responses on the elements to be affected by technology, in SETP. Each word's size indicates its importance or frequency. The most common words were (a) vehicle, (b) management, (c) information, (d) users, (e) collection, (f) implementation, (g) real-time, (h) operation, (i) interval, (j) schedule, which show the trends that the integration of IT services, in transportation, should focus on.

Information provided by the interviewees corroborated that the most relevant services are those aimed at providing information to the system's users. One of the CTO interviewed expressed:

"Part of all this [technology] issue ... it is necessary to start up the information system for the user, this would clearly allow us to have a greater demand of users captured, so that the reliability of the service makes the user feel happier. This important component is one of the most relevant to put into practice".

It is important to mention that the user information system is not considered as a technological component in the SETP, according to the designs and efforts employed by the Colombian government. As mentioned, the main components in the SETP are FMCS and CMS. Considering this, the absence of a user information system as a relevant component for UTS is a very important gap with respect to the improvement and sustainability of transit services in MSC, in developing countries. Therefore, this component should be considered in the next reviews of the progress of SETP implementation in Colombian cities. 


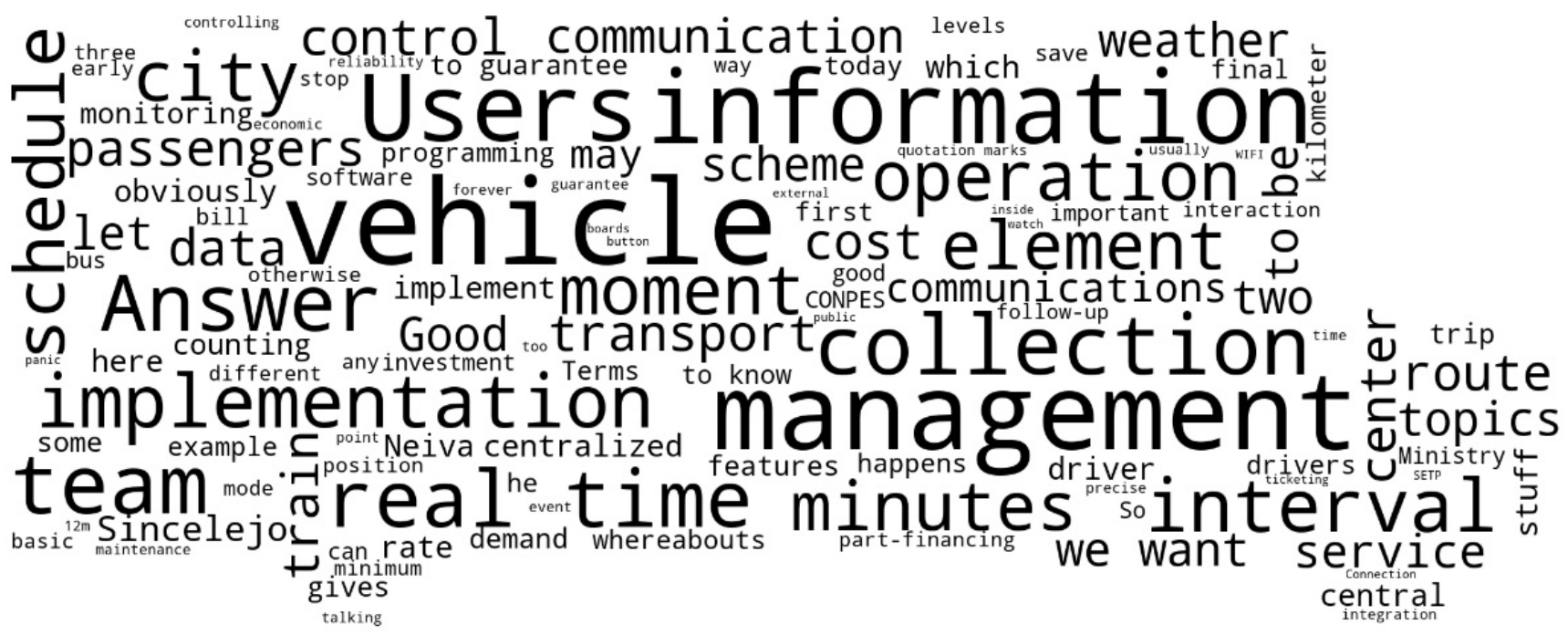

Figure 2. Word cloud associated with responses on technology requirements in transit.

Moreover, there are services associated with the control and compliance of routes by transit drivers. Officials included in their responses such approaches as continuous monitoring of vehicles, speed control, and route compliance. In a SETP, these services are related to the functionalities of the FMCS technological component. In this regard, one of the $\mathrm{COO}$ described it as follows:

"The [technological] functionalities that we have as a minimum for fleet control are: real-time location; traceability through timelines; alarm management where I know if the bus is actually following the route... it has been shown that some drivers do not follow the route, and illegal transportation arrives in this abandoned sector; fleet scheduling; and it is desirable to measure fuel and oil levels of vehicles, it is not necessary but it can be included".

Figure 3 shows the functions associated with transit in MSC that can be strengthened through IT integration. These functionalities are shown according to the relevance established by the interviewees considering the needs of their cities. Based on the results obtained from the complementary questions (5-level Likert scale), the graph indicates a scale of 1 to 5 for each item shown, where 1 is not important and 5 is very important. Thus, this result responds to RQ1.

The results show that all the cities studied homogeneously prioritize the adoption of technology for the delivery of information to users, the drivers' route compliance, and the capture of passenger data. On the contrary, during the processing of the information obtained in the interviews, it was found that functionalities such as continuous fleet monitoring, generation of indicators for city administrators, and vehicle speed control show heterogeneity in technological adoption. While the four MSC located in the south of the country (Armenia, Neiva, Pasto, Popayán) assign a high relevance to these elements, the four MSC located in the north of the country (Valledupar, Santa Marta, Sincelejo, Montería) indicated that these elements have low relevance in their technological integration strategies. This divergence may be caused by cultural differences between the citizens and institutions of both regions, the lack of resources for the project's execution, the economy of each city, and the size of their UTS [26,32,50,51].

Finally, about fleet speed control, one of the interviewees expressed the following comments:

"Today we are having commercial speeds of $16 \mathrm{~km} / \mathrm{h}$. This is because there are a lot of informal vendors, there are a lot of obstacles on the road that limit the speed, so it increases up to $19 \mathrm{~km} / \mathrm{h}$ in commercial speed, so it is not so important [to control it]... because as I know the city, I know it is not so significant". 


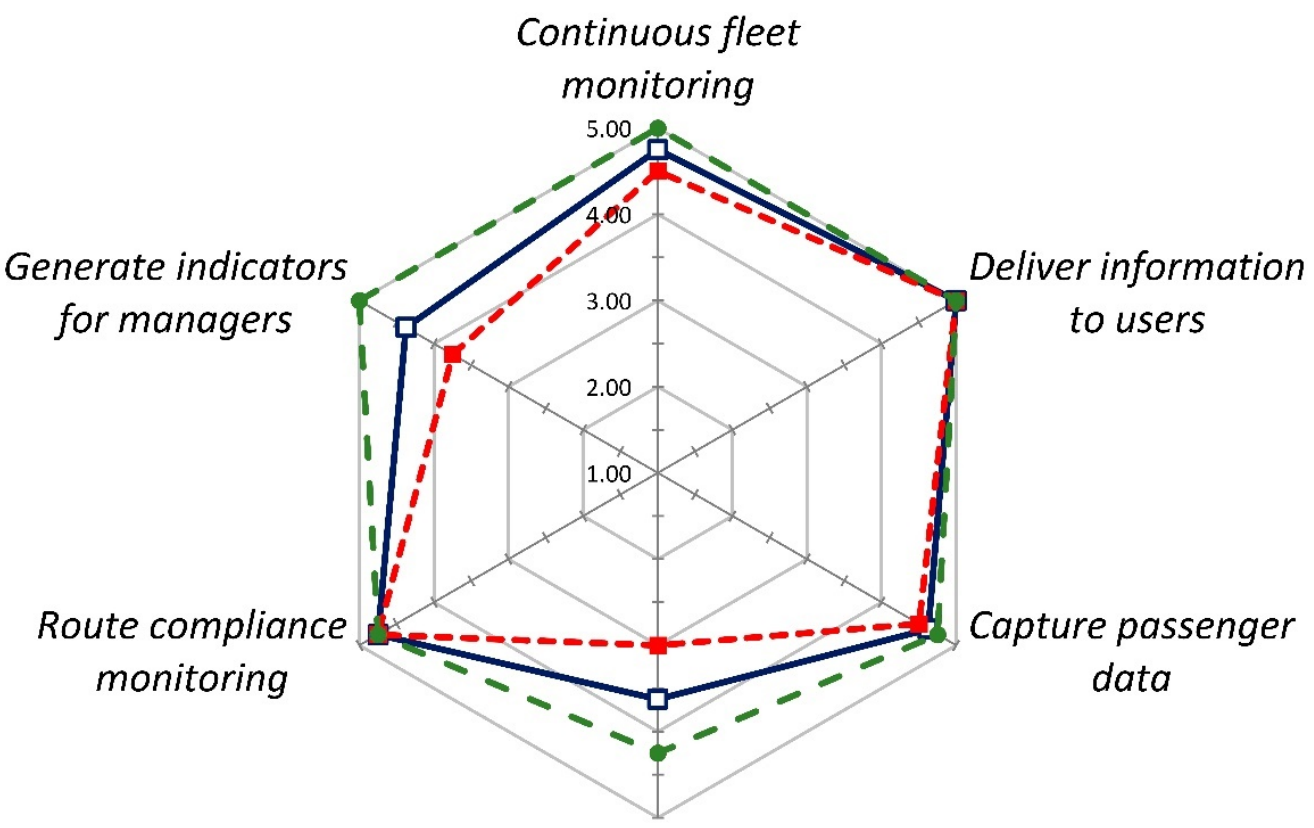

Fleet speed control

\section{$\rightarrow-$ Total Mean $\quad-m-$ Northen Cities Mean $\rightarrow$-Southern Cities Mean}

Figure 3. Relevance of functionalities associated with IT integration in UTS of the Colombian MSC.

With the information provided by the officials interviewed, the functional requirements that IT must address in UTS of Colombian MSC are described, thus responding to $\mathrm{RQ} 2$. All the COO of the SETP interviewed indicated that the functionalities that IT should cover are the following: fleet scheduling; vehicle location and traceability; data storage in the cloud; interoperability with other information systems. Furthermore, seven of the officials interviewed expressed that other functionalities to be covered are: an operations center that allows to control and visualize the data; passenger count; panic button, and management of news of the operation. The functionalities mentioned above were contrasted with the validation information, and the relevance of their implementation through IT was found. Thus, one of the experts interviewed expressed the following:

"When [the vehicle] is already on the road, I have to guarantee the control of the interval [between vehicles]. Then, I must have constant monitoring of where the vehicle is, and for that I must mount all the onboard equipment in the vehicle, and I must have all the equipment on the ground to guarantee that reliability. Then I must have a very reliable onboard system, which cannot be altered by the driver, resistant to vibrations, and a very good communications network to get that information to the ground".

\subsection{Economic Aspect: Investment and Cost of the Technology}

Technology integration projects in UTS, in MSC, require large capital investments in both the acquisition and operation of computer and IT systems. In the context of ITS, technology implementation projects involve operation and maintenance $(\mathrm{O} \& \mathrm{M})$ costs that correspond to $40-55 \%$ of the total budgeted investment [9].

To integrate IT services in UTS, the life cycle of the technologies to be selected must be relevant, considering the level of maturity, the complexity of O\&M, replacement, and final disposal of technological equipment. About, the COO and CTO interviewed affirmed that the computer systems of their UTS should use technologies based on open standards. One of the general comments, expressed by officials, in this category, highlights that "the technologies to be obtained must work with open communication within their protocols, in addition to being configurable in each of the cities, and they must be low-cost and interoperable". 
In this aspect, it is important to note that investments in the technological components of the SETP in each city are already determined by the Colombian government. Through the National Council for Economic and Social Policy (CONPES, in Spanish), budgets were allocated for the main technological components (FMCS, CMS, and in some cities, traffic lights) [13]. However, the technological functionalities to be fulfilled by these technological components are not specified, which may generate erroneous investments by acquiring technologies that are not really needed in these MSC.

Accordingly, considering the low-cost technology approach expressed by the SETP officials interviewed, one of the concerns that arose is the relationship between the quality of the technology and its cost. In this regard, the COO and CTO stated that they require technological solutions for their UTS that they can afford, that are low-cost, but not the cheapest on the market, since the technologies to be acquired must meet the quality requirements demanded by legislation and international standards. When contrasting this requirement with the validation information, one of the experts interviewed expressed the following:

"You have to look at the cost at which the technology guarantees me that the environment
where I am going to mount it, in the vehicle, will withstand it. Yes, they can be inexpensive,
but they must have the necessary resistance for the use I am expecting. There is low-cost
equipment that is very good, but that low cost has a reasonable point, because, in some
cases, the cheapest equipment does not meet all the quality attributes".

Currently, there are low-cost IT alternatives for UTS that can meet the desired requirements for UTS of the MSC studied. Proposals such as (i) use of smartphones and mobile applications for vehicle and user data capture [31,52,53], (ii) use of information collected by vehicle sensors through the onboard diagnostic (OBD) interface [31,54], and (iii) use of low-power, wide-area open communications networks [38,55], are examples of technological solutions with a low-cost approach that can supply the IT requirements, in UTS, in MSC for a SETP.

\subsection{Administrative Aspect: Current Challenges and Technology Decisions}

UTS, in Colombian MSC, faces major challenges related to the decrease in the number of users and the increase in illegal transportation, both of which threaten the sustainability of transit systems. The decrease in the demand for public service in cities and the increase in illegal transportation has been the subject of studies in several cities in the country, these studies have been led by local governments and executed in most cases in the MSC by the UTS companies to which the implementation and operation of the SETP have been assigned. The reasons identified for the low demand for the transit service and the search for other means of transport (such as illegal transportation or motorcycles) are mainly due to the low quality of service perceived by the user. This low quality of the transit service is perceived due to factors such as minimal information to the user about routes and schedules, non-compliance with routes, insecurity in the use of the service (due to high vehicle speeds, or inadequate driving, in some cases), stops at places not allowed (to pick up and drop off passengers), low availability at certain times of the day.

Moreover, to the two drawbacks stated (decrease in the number of users and the increase of illegal transportation) is added the effects caused by the COVID-19 pandemic, limiting the number of passengers that can enter the system to maintain social distance. The general results of the Urban Passenger Transportation Survey conducted by the National Administrative Department of Statistics (DANE, in Spanish) of Colombia show that, during the first quarter of 2021, the number of passengers transported by transit systems had a decrease of $34.2 \%$ compared to the first quarter of 2020 [56].

Figure 4 shows the number of passengers needed to operate the transit systems of seven of the cities studied, it also shows the number of passengers that were transported before and after the start of the COVID-19 emergency. Except for one city, note that the number of users transported by the UTS, in MSC, does not meet the minimum number of passengers of the system to make its commercial operation sustainable without economic limitations. Although it is important to consider that impact generated on the demand for 
the transit service by the COVID-19 pandemic is temporary and it is expected that in the coming months this effect will decrease considerably, the reality is that the use of the transit service has a downward trend, for the two reasons stated initially.

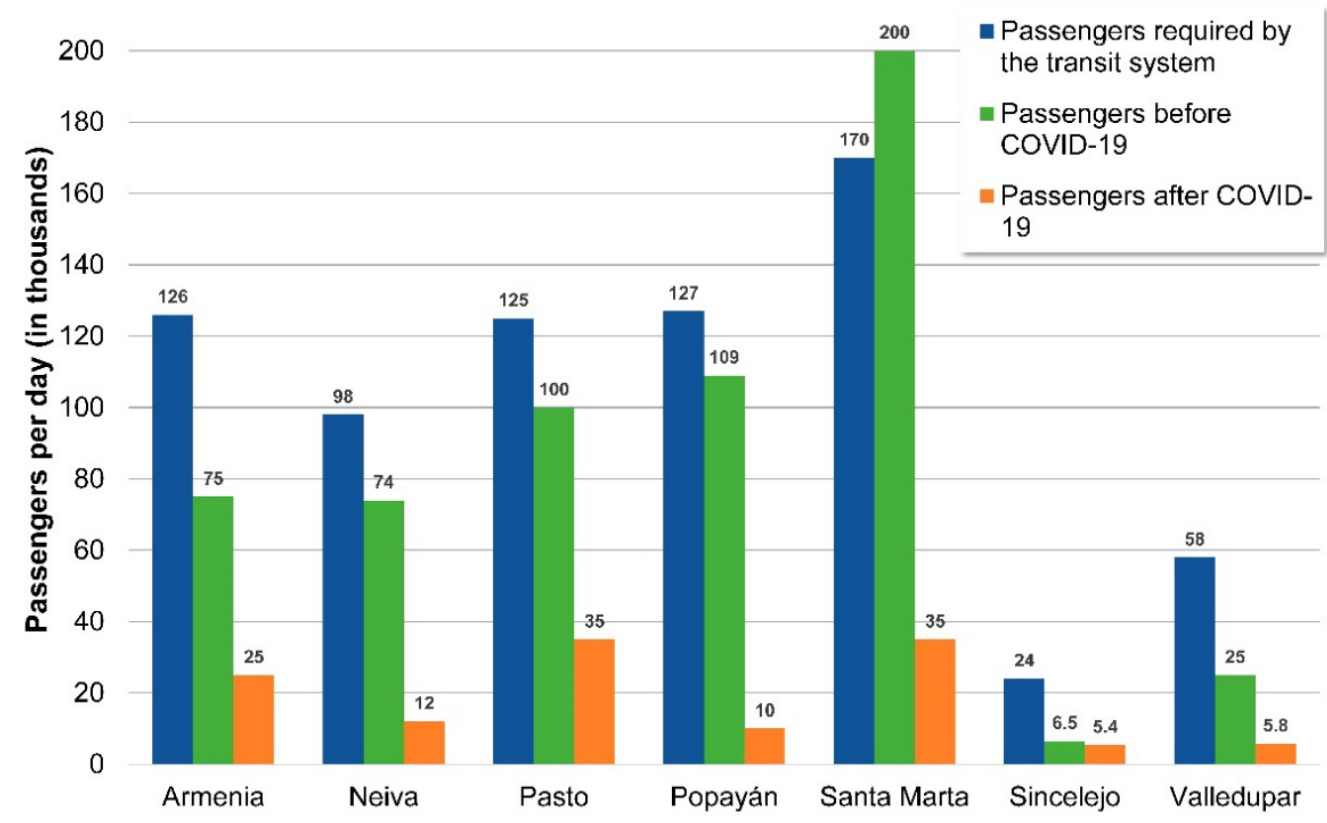

Data provided by SETPs in November 2020

Figure 4. The number of passengers transported by transit systems in Colombian MSC.

Faced with financial challenges due to the lack of transit users, municipal governments provide resources to the system through fare stabilization funds. The officials interviewed stated that this strategy seeks to maintain the sustainability of the transit system while encouraging more users to join the system. About, one of the COO commented that, in his city, the following is happening:

"With the current demand conditions [of the system], the project does not close financially yet, since the tariff that should be charged for the use of transportation should be double what it is set today. Therefore, the tariff stabilization fund is being contemplated to be able to make that contribution that is necessary to cover the operation [of the system]".

To attract and maintain more passenger demand for transportation, it is necessary to implement better quality and comfort attributes in the UTS [57] of MSC. These attributes include the availability of WiFi networks in stations; mobile applications to reduce waiting times; innovative ticketing systems; competitive fees through new financing models for operating costs; among others [58]. In this scenario, the SITM experts interviewed said:

"We must begin to differentiate revenues, because [the transportation system] cannot continue to live only on user fees. The company has the goal that non-fare revenues, such as advertising and commercial space, reach $15 \%$ in the coming years. Today we are at $12 \%$, but that is the call to all transportation companies, they cannot live only on user fees".

From an administrative point of view, the COO and CTO interviewed stated that the integration of IT services, in their UTS, should help capture new users and mitigate the impacts produced by illegal transportation. Together with the economic aspect, this aspect responds to RQ3. This can be achieved by following the proposals provided by studies conducted in Latin America, which generate practical recommendations on technologies for urban transportation and public-private operation schemes, to generate added value to Latin American cities [59]. 


\section{Discussion}

This paper provided an empirical experimental approach, with the participation of 15 officials (COO, CTO, and others), from the eight MSC that correspond to all the municipalities implementing a SETP in Colombia. One expert from an intelligent transportation system in a capital city also participated. The study found the requirements and prioritizations that each transit system wishes to achieve with IT support. Particularly, by taking an orientation towards inference procedures with connections between the empirical and theoretical domains [49] and employing a series of general theories, a group of conceptional variables that can be measured empirically was recognized. Based on this, key categories have been identified and defined for the integration of IT services, in UTS, in Colombian MSC.

In the technological aspect, it was found the needs that the UTS of the analyzed cities aim to implement with the support of information technologies. This category raises questions related to the level of technology required by these cities, whether the identified needs can be met by implementing mature technologies, emerging technologies, or technologies that do not yet exist [59]. The concepts expressed by the interviewees indicate that the services prioritized for implementation can be implemented with existing technologies that have a high degree of maturity (e.g., driver monitoring systems, automotive real-time data analytics) and technologies with high expectations in the medium future (e.g., mobility as a service, 5G networks, blockchain, Internet of Things) [60], which can meet the functional requirements desired by SETP.

The economic aspect shows the low-cost approach desired by the cities studied for their UTS. This is an approach based on the services offered to transit users rather than an approach based purely on technology, which is only there to support the service [54]. The concepts that saturate this category show the need to implement technical systems that SETP investors can afford and that meet the quality requirements demanded by current legislation. Interviewees expressed strong interest in technologies based on both open source and open standardized network protocols as options to integrate technology solutions into their transit systems. This perspective presents an advantage over the use of closed technologies generally offered by suppliers, who create a monopoly over the system and impose unfavorable conditions for scalability, maintenance, and replacement of the technology [9]; as an example, is the use of LoRaWAN for data transmission in UTS, which works in a cost-free unlicensed spectrum, in contrast to Sigfox, which offers longer communication range but has subscription costs for the service [61].

The administrative aspect shows what decision-makers of the transit systems studied have contemplated facing common challenges, such as: increasing the number of passengers mobilized by the system, reducing the supply of illegal transportation, and recovering the economic losses caused by the COVID-19 pandemic. Interviewees emphasized improving the quality of service by adding value through improving the user's comfort and experience when interacting with the system $[9,62]$.

There is a contrast point between the prioritizations established by the northern cities of the country (Valledupar, Santa Marta, Sincelejo, Montería) and the decisions prioritized by the southern cities of the country (Armenia, Neiva, Popayán, Pasto), as shown in Figure 2. This contrast may have its origin in the economic, socio-cultural, and environmental differences of the populations [63], in addition to the high dependence of some of these cities on public resources [64].

Another strong reason for the contrast found between these MSC is due to the size of the UTS, considering the number of inhabitants in each city -and, therefore, the number of users of the transit system - where most of the cities in the north of the country have a population of approximately 500,000 inhabitants, while the cities in the south of the country have a much smaller population. An additional reason for this contrast may be the speed of transit vehicles in some areas of the cities located in the south of the country. For example, in the city of Popayán, Colombia in some areas covered by transit routes, these vehicles can reach speeds of up to $100 \mathrm{~km} / \mathrm{h}$ during certain hours. Consequently, driving transit 
vehicles above the operating speed limit $(60 \mathrm{~km} / \mathrm{h})$ generates accidents and is detrimental to road safety [55].

The mentioned contrast between cities, according to their geographic location, is an observable trend related to the capacity of municipal authorities, in MSC -in Latin American countries such as Argentina, Bolivia, Brazil, Colombia, Chile, Ecuador, and Peruto respond to the needs of inhabitants by managing technical, administrative, and financial resources for decision making related to local collective welfare and sustainability [65]. Therefore, digital transformation in the transportation sector-such as the inclusion of IT services in UTS - must also promote the economic and cultural growth of these cities.

Results obtained in this research represent a significant contribution to future research (in academic implications) related to ITS services for the transit service in developing countries. The most relevant functionalities of this service were identified, to achieve an improvement for the UTS companies in charge of managing it. Additionally, the technological panorama, that these companies consider necessary to perform an adequate control and management of the transit service, was identified. This information is useful for related research projects, to properly focus on the type of relevant functionality in the transit service and technology that is required to implement such functionality considering technical and economic issues.

Additionally, the results of this research represent an important input for the operation performed by the UTS companies (in the practical implications) of the transit service, since they can assign priorities to the most relevant functionalities and achieve an improvement or a prompt implementation (in case of not having them developed). Additionally, the UTS companies can compare their functional priorities and the implemented technologies, with those determined by the other UTS that operate in the other cities of the country.

Finally, during the design and development of this study was addressed the search for categories related to environmental and social aspects $[39,57,66]$ in the analyzed transit systems. However, no findings directly saturating these categories were found in the interviews. Several interviewees made inferences in these two categories when expressing their answers to the questions, stating that positive results will be achieved for these through the categories described above (technological, economic, administrative).

\section{Conclusions}

This research identified the key aspects that should be considered when integrating IT services, in UTS, in Colombian MSC. During the interviews conducted, it was found a great interest on the part of the officials interviewed to improve UTS, in the case study cities, with the help of cutting-edge technological solutions. In such solutions, technological, economic, and administrative aspects play an important role in the study phase prior to the implementation of IT services aimed to deliver information to users, route compliance, and data capture of users and vehicles.

Improved service delivery through the integration of IT services can encourage (i) greater use of public transportation, (ii) increase the number of users transported per day, and (iii) achieve the sustainability goals established for each system. With the results obtained in this research, it is possible to present recommendations on technologies and IT services to complete the SETP implementation in the eight MSC analyzed, and in other MSC of similar characteristics at the national and international level. It is important to consider the existing differences between the prioritizations of the technological aspect in the cities studied and their relationship with their geographical location (north/south) because including socio-cultural and economic characteristics of the population can guide the design of suitable strategies for IT-services integration in transit service. These recommendations may also be applied to plan the integration of IT services in the four Colombian cities that are designing their strategic transportation systems, and to other MSC in other developing countries. 
For the next stages of this research, it is proposed as a recommendation the design an IT service that covers the implementation of the user information system needed and requested by the UTS of Colombian MSC. This user information system should be interoperable and strongly related to the FMCS. Likewise, it is recommended to conduct interviews with officials of the transit systems studied with questions oriented to the integration of O\&M policies, to identify technologies that can improve both areas of the system.

Furthermore, for future research, it is suggested that a comparative analysis be made with similar UTS located in other regions, such that the sample of MSC studied be expanded to include a significant number of populations worldwide, and the use of quantitative analysis techniques can be included to explore common patterns that favor IT-services integration in UTS, in MSC, in developing countries. Considering that some of the statements expressed in the results of this paper could also apply to large-sized cities in Colombia, it is suggested as future work, to perform an investigation focused on cities of another size (mainly large-sized cities) to validate if the results obtained also apply to this type of cities.

Author Contributions: Conceptualization, T.R.-G., M.T. and R.S.-C.; methodology, T.R.-G.; validation, T.R.-G., M.T., M.S.T., R.S.-C. and Á.P.d.l.C.; formal analysis, T.R.-G. and M.T.; investigation, T.R.-G.; resources, M.T. and M.S.T.; data curation, T.R.-G.; writing-original draft preparation, T.R.-G.; writing-review and editing, M.T., M.S.T., R.S.-C. and Á.P.d.I.C.; visualization, T.R.-G.; supervision, M.T.; project administration, M.T.; funding acquisition, M.T.; All authors have read and agreed to the published version of the manuscript.

Funding: This research received no external funding.

Institutional Review Board Statement: Not applicable.

Informed Consent Statement: Informed consent was obtained from all subjects involved in the study.

Data Availability Statement: Not applicable.

Acknowledgments: Authors are very grateful for the support provided by Universidad EAFIT (Vicerrectoría de Descubrimiento y Creación), Universidad del Cauca (Telematics Department) and Universidad Icesi (ICT Department), and the information provided by the government companies of the SETP, in Colombia, for this research. T.R.-G. also extend thanks to MSc. Leidy Marcela Dueñas Ramírez for constructive advice during the methodology stages, and to the undergraduate students of the Semillero SiSIT and Semillero SIME, for their help to transcribe, preprocess, and organize the information collection during the interviews.

Conflicts of Interest: The authors declare no potential conflicts of interest.

\section{Appendix A}

Table A1 contains the interview guide used during the sessions with the Chief Operating Officers and Chief Technology Officers interviewed. Sections 1-3 correspond to the 16 core questions of this study.

Table A1. User interview guide.

\begin{tabular}{ll}
\hline Section & Questions \\
\hline
\end{tabular}

1. Introductory questions: Exploration about the profile of the participants
- Would you tell me about yourself?

- What has your experience been like as a SETP [position] in your city? 
Table A1. Cont.

\begin{tabular}{|c|c|}
\hline Section & Questions \\
\hline $\begin{array}{l}\text { System operation: Exploring specific details on } \\
\text { operational aspects }\end{array}$ & 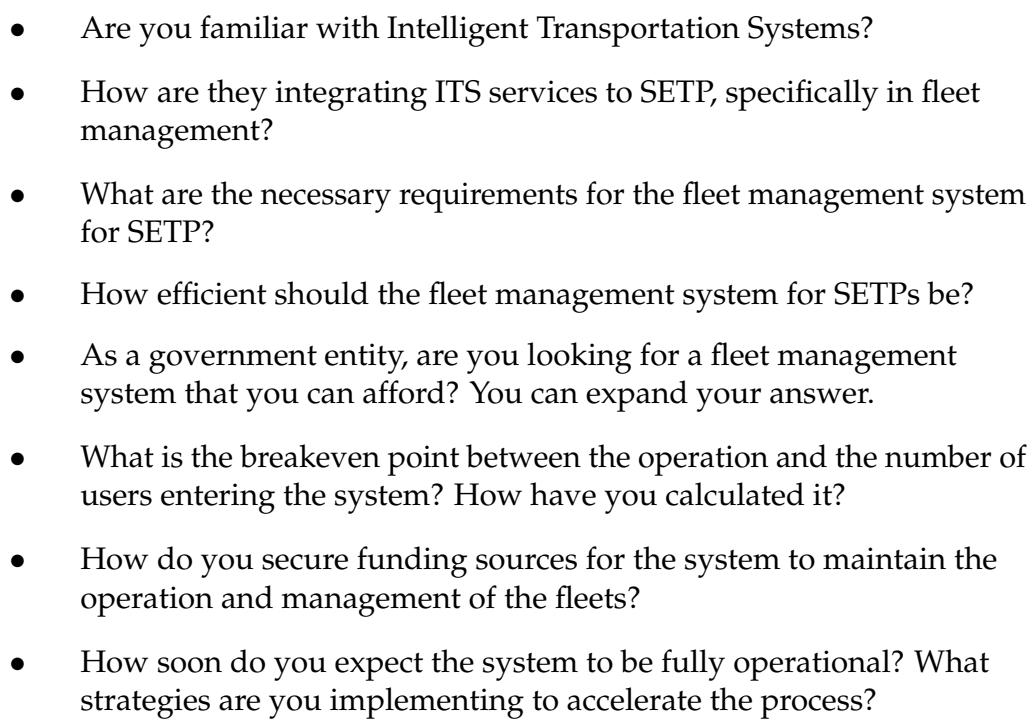 \\
\hline $\begin{array}{l}\text { Technology resources: Exploring specific } \\
\text { details about the technology required by } \\
\text { the system. }\end{array}$ & $\begin{array}{l}\text { What are the sources of information and how should the information } \\
\text { flow in the fleet management system? } \\
\text { Do you think there is a need for custom-designed fleet management } \\
\text { technology solutions for SETPs? Why? } \\
\text { - Which technologies have you studied for SETP fleet management? } \\
\text { Which have you selected? } \\
\text { - Do you think that the quality of the technology to be acquired is } \\
\text { related to its price? } \\
\text { - What do you think of low-cost vehicle tracking systems? } \\
\text { How are you applying international standards for technology } \\
\text { integration in fleet management? }\end{array}$ \\
\hline
\end{tabular}

- $\quad$ From 1 to 5 , being 5 the highest, indicate the relevance of the following approaches:

- Continuous monitoring of the vehicles during their route

- $\quad$ Provide the user with information about the routes provided, arrival times, frequencies, etc.

4. Complementary closed questions: Estimating the relevance of functional requirements.
- Obtain information on passengers in the vehicle, entry and exit of the passengers.

- Monitoring the speed of fleets.

- Control compliance with the routes assigned to vehicles and unauthorized stops.

- $\quad$ Provide managers with statistical information on the use and compliance of the system.

- Is there anything else we did not discuss that is important about SETPs? 


\section{References}

1. Houghton, J.; Reiners, J.; Colin, L. Transporte Inteligente-Cómo Mejorar la Movilidad en las Ciudades; IBM Institute for Business Value: New York, NY, USA, 2009.

2. Martínez Toro, E.E.; van der Krogt, A.; Sánchez Flores, R. Mobility and Integration of Public Transport Systems in Latin America. In Proceedings of the 2nd International Conference on Machine Learning and Machine Intelligence, Jakarta, Indonesia, 18-20 September 2019; ACM Press: New York, NY, USA, 2019; pp. 58-62.

3. Martinod, R.M.; Rezg, N.; Castaneda, L.F.; Bistorin, O. Combined optimization methodology for operational planning and service policies: A case study of urban ropeway transport. Int. J. Transp. Econ. 2020, 42, 337-363. [CrossRef]

4. $\quad$ Siemens, S.A. Soluciones Inteligentes Para el Tráfico de Hoy y Del Mañana; Siemens: Madrid, Spain, 2008.

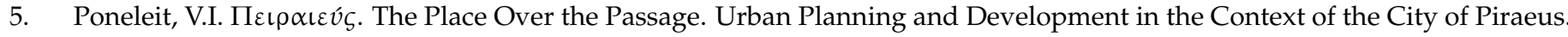
Master's Thesis, Politecnico di Milano, Milan, Italy, 2019.

6. Tiwari, G. Urban transportation planning. In Sustainable Approaches to Urban Transport; Mohan, D., Tiwari, G., Eds.; CRC Press: Boca Raton, FL, USA, 2019; pp. 1-13.

7. Banco de Desarrollo de América Latina. Ciudades Intermedias y Desarrollo en América Latina. Available online: https: / / bit.ly/3tHagk9 (accessed on 20 November 2021).

8. Gómez-Lobo, A. Transit reforms in intermediate cities of Colombia: An ex-post evaluation. Transp. Res. Part A Policy Pract. 2020, 132, 349-364. [CrossRef]

9. GSD+. Esquemas de Implantación de Tecnologías Inteligentes de Transporte en América Latina: Estudios de Casos y Recomendaciones; Banco de Desarrollo de América Latina: Caracas, Venezuela, 2019; ISBN 978-980-422-130-9.

10. Ministerio de Transporte. Decreto 3422 de 2009 Reglamentación de los Sistemas Estratégicos de Transporte Público; Ministerio de Transporte: Bogotá, Colombia, 2009.

11. Rodríguez Porcel, M.; Bernal González, J.; Beltrán Real, Ó.M. Programa de Sistemas Estratégicos de Transporte Público (SETP). Caso de Estudio: Colombia; Banco Interamericano de Desarrollo: Washington, DC, USA, 2018.

12. Ministerio de Transporte. Decreto 2060 de 2015 Definiciones de los Sistemas Inteligentes de Transporte; Ministerio de Transporte: Bogotá, Colombia, 2015.

13. Departamento Nacional de Planeación. CONPES 3833 Seguimiento a los Sistemas de Transporte Público, Ajuste del Perfil de Aportes y Recomposición de Componentes; Departamento Nacional de Planeación: Bogotá, Colombia, 2015.

14. Jehanno, A.; Niang, H.; Ortíz, J.; Laborde, P.; López Camacho, P. Desafíos Para la Integración de Sistemas de Transporte Masivo: Manual de Buenas Prácticas; Bando de Desarrollo de América Latina: Caracas, Venezuela, 2019.

15. Quiñones, L.M.; Van Laake, T. El estado del transporte urbano en América Latina. In Transporte Urbano Sostenible en América Latina: Evaluaciones y Recomendaciones para Politicas de Movilidad; Moscoso, M., Van Laake, T., Quiñones, L.M., Pardo, C.F., Hidalgo, D., Eds.; Despacio: Bogotá, Colombia, 2019; pp. 11-18.

16. Toro-González, D.; Cantillo, V.; Cantillo-García, V. Factors influencing demand for public transport in Colombia. Res. Transp. Bus. Manag. 2020, 36, 100514. [CrossRef]

17. Ministerio de Transporte. Transporte en Cifras Vigencia 2019; Ministerio de Transporte: Bogotá, Colombia, 2020.

18. Medellín, P. Sistemas de Transporte Público, Entre Crisis y Cambios. Available online: https://bit.ly/3hwPE9m (accessed on 20 November 2021).

19. Stavros, J.M.; Sprangel, J.R. "SOAR" from the Mediocrity of Status Quo to the Heights of Global Sustainability. In Innovative Approaches to Global Sustainability; Wankel, C., Stoner, J.A.F., Eds.; Palgrave Macmillan: New York, NY, USA, 2008.

20. Roth, A.; Kåberger, T. Making transport systems sustainable. J. Clean. Prod. 2002, 10, 361-371. [CrossRef]

21. Barbero, J.A.; Rodríguez Tornquist, R. Transporte y cambio climático: Hacia un desarrollo sostenible y de bajo carbono. Rev. Transp. Territ. 2012, 8-26.

22. Janic, M. Sustainable Transport in the European Union: A Review of the Past Research and Future Ideas. Transp. Rev. 2006, 26, 81-104. [CrossRef]

23. Janić, M. Advanced Transport Systems; Springer: London, UK, 2014.

24. Park, E.; del Pobil, A.; Kwon, S.J. The Role of Internet of Things (IoT) in Smart Cities: Technology Roadmap-oriented Approaches. Sustainability 2018, 10, 1388. [CrossRef]

25. Adeleke, O.O.; Jimoh, Y.A.; Akinpelu, M.A. Development of an advanced public transportation system for captive commuters on urban arterials in Ilorin, Nigeria. Alex. Eng. J. 2013, 52, 447-454. [CrossRef]

26. Concha, J.; Camós, G. Sistemas de Transporte Urbano: Lecciones Aprendidas Desde la Perspectiva de la Prestación del Servicio. Caso de Estudio: Colombia; Banco Interamericano de Desarrollo: Washington, DC, USA, 2019.

27. Valencia, J.; Ramirez-Guerrero, T.; Castañeda, L.; Toro, M. Detección de infracciones y matrículas en motocicletas, mediante visión artificial, aplicado a Sistemas Inteligentes de Transporte. RISTI Rev. Iber. Sist. Tecnol. Inf. 2020, 37, 1-15. [CrossRef]

28. Valencia, J.; Ramirez-Guerrero, T.; Castañeda, L.F.; Toro, M. Automatic detection of number-plate and traffic infractions of motorcyclists by Intelligent Transportation Systems. IOP Conf. Ser. Mater. Sci. Eng. 2020, 844, 012035. [CrossRef]

29. Sagbini, K.; Ramirez-Guerrero, T.; Castañeda, L.; Toro, M. Aplicaciones Móviles para la Evaluación de Conductores y Usuarios en Sistemas Estratégicos de Transporte Público. In Desafíos en Ingeniería: Investigación Aplicada; Rojas Martínez, L., Ed.; Fundación Universitaria Antonio de Arévalo: Cartagena de Indias, Colombia, 2019; pp. 184-190. 
30. Ramirez-Guerrero, T.; Toro, M.; Villegas López, G.; Castañeda, L. Functional Requirements for Management and Control of Public Transportation Vehicles, Applied to Sustainable Mobility in Medium-Sized Cities. In Communication, Smart Technologies and Innovation for Society; Rocha, Á., López-López, P.C., Salgado-Guerrero, J.C., Eds.; Smart Innovation, Systems and Technologies; Springer: Singapore, 2022; Volume 252, pp. 673-683.

31. Ramirez-Guerrero, T.; Toro, M.; Villegas López, G.A.; Castañeda, L.F. Low-cost computational systems applied to physical architectures in public transportation systems of intermediate cities. J. Phys. Conf. Ser. 2020, 1702, 012018. [CrossRef]

32. Fundación Ciudad Humana; Montezuma, R.; Fonseca, S. Plan Integral de Movilidad no Motorizada y Espacio Público para Valledupar; Bando de Desarrollo de América Latina: Caracas, Venezuela, 2018.

33. Salazar-Cabrera, R.; Pachón de la Cruz, A. Design of Urban Mobility Services for an Intermediate City in a Developing Country, Based on an Intelligent Transportation System Architecture. In Applied Computer Sciences in Engineering. WEA 2018; FigueroaGarcía, J.C., Villegas, J.G., Orozco-Arroyave, J.R., Maya Duque, P.A., Eds.; Communications in Computer and Information Science; Springer: Cham, Switzerland, 2018; Volume 916, pp. 183-195.

34. U.S. Department of Transportation. Architecture Reference for Cooperative and Intelligent Transportation (ARC-IT v9.0); U.S. Department of Transportation: Washington, DC, USA, 2021.

35. Rojas, B.; Bolaños, C.; Salazar-Cabrera, R.; Ramírez-González, G.; Pachón de la Cruz, Á.; Madrid Molina, J.M. Fleet Management and Control System for Medium-Sized Cities Based in Intelligent Transportation Systems: From Review to Proposal in a City. Electronics 2020, 9, 1383. [CrossRef]

36. Salazar-Cabrera, R.; Pachon De La Cruz, A.; Madrid Molina, J.M. Fleet management and control system from intelligent transportation systems perspective. In Proceedings of the 2nd Latin American Conference on Intelligent Transportation Systems, Bogotá, Colombia, 19-20 March 2019; IEEE: New York, NY, USA, 2019; pp. 1-7.

37. Buele, J.; Salazar, L.F.; Altamirano, S.; Aldás, R.A.; Urrutia-Urrutia, P. Plataforma y aplicación móvil para proporcionar información del transporte público utilizando un dispositivo embebido de bajo costo. RISTI Rev. Iber. Sist. Tecnol. Inf. 2019, E17, 476-490.

38. Jurado Murillo, F.; Quintero Yoshioka, J.S.; Varela López, A.D.; Salazar-Cabrera, R.; Pachón de la Cruz, Á.; Madrid Molina, J.M. Experimental Evaluation of LoRa in Transit Vehicle Tracking Service Based on Intelligent Transportation Systems and IoT. Electronics 2020, 9, 1950. [CrossRef]

39. Gonzalez, R.A.; Ferro, R.E.; Liberona, D. Government and governance in intelligent cities, smart transportation study case in Bogotá Colombia. Ain Shams Eng. J. 2020, 11, 25-34. [CrossRef]

40. Abduljabbar, R.; Dia, H.; Liyanage, S.; Bagloee, S.A. Applications of Artificial Intelligence in Transport: An Overview. Sustainability 2019, 11, 189. [CrossRef]

41. Corbin, J.; Strauss, A. Basics of Qualitative Research: Techniques and Procedures for Developing Grounded Theory, 4th ed.; SAGE Publications: Thousand Oaks, CA, USA, 2014.

42. Langley, A.; Klag, M. Being Where? Navigating the Involvement Paradox in Qualitative Research Accounts. Organ. Res. Methods 2019, 22, 515-538. [CrossRef]

43. Penalva Verdú, C.; Alaminos Chica, A.; Francés García, F.J.; Santacreu Fernández, Ó.A. La Investigación Cualitativa: Técnicas de Investigación y Análisis con Atlas.ti, 1st ed.; PYDLOS Ediciones: Cuenca, Ecuador, 2015.

44. Congreso de la República. Ley 1540 de 2011 Plan Nacional de Desarrollo 2010-2014: Prosperidad para Todos; Congreso de la República: Bogotá, Colombia, 2011.

45. Hernán-García, M.; Lineros-González, C.; Ruiz-Azarola, A. Cómo adaptar una investigación cualitativa a contextos de confinamiento. Gac. Sanit. 2021, 35, 298-301. [CrossRef]

46. Ramirez-Guerrero, T.; Castañeda, L.; Toro, M. Sistema inteligente para transporte público tipo SETP. In XIII Congreso Colombiano de Transporte y Tránsito. Movilizando el Futuro de Colombia; Vélez-Pereira, A.M., Toro-González, D., Eds.; Universidad Tecnológica de Bolívar: Cartagena de Indias, Colombia, 2019; p. 57.

47. Portigal, S. Interviewing Users: How to Uncover Compelling Insights; Rosenfeld Media: New York, NY, USA, 2013.

48. Arnold, W.E.; McCroskey, J.C.; Prichard, S.V.O. The Likert-type scale. Today's Speech 1967, 15, 31-33. [CrossRef]

49. Spiggle, S. Data in Consumer Research. J. Consum. Res. 1994, 21, 491-504. [CrossRef]

50. Sánchez-Jabba, A.M. La Economía del Mototaxismo: El Caso de Sincelejo; Banco de la República: Bogotá, Colombia, 2011.

51. Cardona, S.; Escobar, D.; Moncada, C. Evolución del número de pasajeros movilizados en los Sistemas Estratégicos de Transporte Público en Colombia. Análisis cuantitativo. Rev. Espac. 2017, 38, 11-24.

52. Simonyi, E.; Fazekas, Z.; Gáspár, P. Smartphone application for assessing various aspects of urban public transport. Transp. Res. Procedia 2014, 3, 185-194. [CrossRef]

53. World Road Association. Low Cost ITS_Case Studies; World Road Association: Paris, France, 2019; ISBN 978-2-84060-511-9.

54. World Road Association. Low Cost ITS.; World Road Association: Paris, France, 2019; ISBN 978-2-84060-510-2.

55. Salazar-Cabrera, R.; Pachón De La Cruz, A.; Madrid Molina, J.M. Proof of Concept of an IoT-Based Public Vehicle Tracking System, Using LoRa (Long Range) and Intelligent Transportation System (ITS) Services. J. Comput. Networks Commun. 2019, 2019, 10. [CrossRef]

56. Departamento Administrativo Nacional de Estadística. Encuesta de Transporte Urbano de Pasajeros (ETUP)—Boletín Técnico Primer Trimestre de 2021; DANE: Bogotá, Colombia, 2021.

57. Chica-Olmo, J.; Gachs-Sánchez, H.; Lizarraga, C. Route effect on the perception of public transport services quality. Transp. Policy 2018, 67, 40-48. [CrossRef] 
58. Salas-Rondón, M.; Jiménez-Serpa, J.C.; Martínez-Estupiñán, Y.F. Subsidio a la tarifa para fortalecer la operación de los sistemas estratégicos de transporte público en Colombia. Rev. UIS Ing. 2021, 20, 77-90. [CrossRef]

59. GSD+. Esquemas de Implantación de Tecnologías Inteligentes de Transporte en América Latina: Estado Actual y Avances en el Ámbito Urbano; Banco de Desarrollo de América Latina: Caracas, Venezuela, 2019; ISBN 978-980-422-131-6.

60. Gartner Inc. Hype Cycle for Transportation Industry; Gartner Inc.: New York, NY, USA, 2020.

61. Bertoldo, S.; Carosso, L.; Marchetta, E.; Paredes, M.; Allegretti, M. Feasibility analysis of a lora-based wsn using public transport. Appl. Syst. Innov. 2018, 1, 49. [CrossRef]

62. Beirão, G.; Sarsfield Cabral, J.A. Understanding attitudes towards public transport and private car: A qualitative study. Transp. Policy 2007, 14, 478-489. [CrossRef]

63. Duque-Cante, N.; Moncayo-Jiménez, E. Descentralización Administrativa y Categorización Municipal en Colombia. Rev. Bras. Gestão Desenvolv. Reg. 2020, 16, 136-150.

64. Cortés, D.; Vargas, J.F. Inequidad Regional en Colombia. Doc. CEDE 2012, 34, 1-76.

65. Rodríguez, A.; Velásquez, F. Municipio y Servicios Públicos: Gobiernos Locales en Ciudades Intermedias de América Latina, 1st ed.; Colección Estudios Urbanos; Ediciones Sur: Santiago de Chile, Chile, 1994.

66. Farag, S.; Lyons, G. What affects use of pretrip public transport information? Empirical results of a qualitative study. Transp. Res. Rec. J. Transp. Res. Board 2008, 85-92. [CrossRef] 